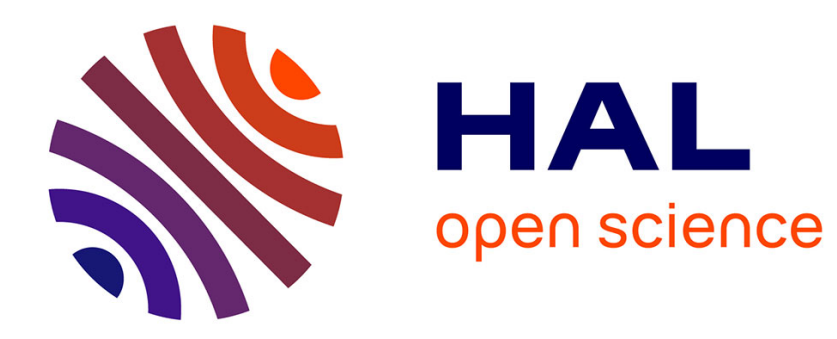

\title{
Effect of porosity on electrical conductivity of hot pressed AlN ceramic
}

\author{
M. Zulfequar, A. Kumar
}

\section{To cite this version:}

M. Zulfequar, A. Kumar. Effect of porosity on electrical conductivity of hot pressed AlN ceramic. Revue de Physique Appliquée, 1986, 21 (9), pp.525-529. 10.1051/rphysap:01986002109052500 . jpa00245470

\section{HAL Id: jpa-00245470 https://hal.science/jpa-00245470}

Submitted on 1 Jan 1986

HAL is a multi-disciplinary open access archive for the deposit and dissemination of scientific research documents, whether they are published or not. The documents may come from teaching and research institutions in France or abroad, or from public or private research centers.
L'archive ouverte pluridisciplinaire HAL, est destinée au dépôt et à la diffusion de documents scientifiques de niveau recherche, publiés ou non, émanant des établissements d'enseignement et de recherche français ou étrangers, des laboratoires publics ou privés. 


\title{
REVUE DE PHYSIQUE APPLIQUÉE
}

Revue Phys. Appl. 21 (1986) 525-529

SEPTEMBRE 1986, PAGE 525

Classification

Physics Abstracts

$81.40 \mathrm{R}$

\section{Effect of porosity on electrical conductivity of hot pressed AIN ceramic (*)}

\author{
M. Zulfequar and A. Kumar \\ Department of Physics, Harcourt Butler Technological Institute, Kanpur, 208002, India
}

(Reçu le 19 février 1986, révisé le 18 avril, accepté le 23 mai 1986)

\begin{abstract}
Résumé. - La dépendance en température de la conductivité électrique a été étudiée pour une céramique AlN pressée à chaud ayant divers pourcentages de porosité en volume $(0,2$ à $15 \%)$ dans l'intervalle de température de 500 à $950 \mathrm{~K}$. Il a été observé que la conductivité électrique décroît de deux ordres de grandeur quand le pourcentage de porosité en volume passe de 0,2 à $15 \%$. L'effet de l'humidité sur la conductivité électrique a aussi été étudié sur les mêmes échantillons d'AIN. Les échantillons ayant une petite porosité (jusqu'à $4 \%$ en volume) ne présentent aucun effet appréciable de l'humidité sur la conductivité électrique. Toutefois, à porosité plus grande $(15 \%$ en volume), la conductivité s'accroît de trois ordres de grandeur après exposition à l'humidité.
\end{abstract}

\begin{abstract}
Temperature dependence of electrical conductivity has been studied for hot pressed AlN ceramic having different volume percentage of porosity ( 0.2 to $15 \%)$ in the temperature range $(500 \mathrm{~K}$ to $950 \mathrm{~K})$. It has been observed that electrical conductivity decreases by two orders of magnitude as the volume percentage of porosity increases from 0.2 to $15 \%$. The effect of moisture on electrical conductivity has also been studied on the same samples of AlN. Samples having small porosity (upto 4 volume \%) did not show any appreciable effect of moisture on electrical conductivity. However, at higher concentration of porosity (15 volume $\%)$, the conductivity increases by three orders of magnitude after exposing to the moisture.
\end{abstract}

\section{Introduction.}

Kohn and his associates [1] at US Bureau of Mines first found that small crystals of aluminium nitride (AIN), prepared at high temperatures, were inert to hot and cold mineral acids and alkali solutions. Other workers who found aluminium nitride a relatively stable material are Rey [2], Renner [3] and Long and Foster [4]. It is now well established that aluminium nitride, prepared at high temperatures, is quite stable and may have application as refractory. The mechanical properties of this material has been studied in detail [5-8] but not much work have been done on electrical properties. One of us studied the dielectric behaviour of hot pressed AlN ceramic with and without additives and found [9] that dielectric losses are appreciable

(*) Work supported by Council of Scientific and Industrial Research, New Delhi, India. only at low frequencies and high temperatures. This study showed that AlN can also be used as a dielectric material in capacitors. The electrical conductivity measurements, particularly at high temperatures, are very important to check the insulating ability of hot pressed AlN ceramic at high temperatures. The porosity is an important parameter on which the electrical conductivity may depend. A study of the effect of moisture on electrical conductivity is also important if one uses this material for insulation.

The aim of the present work is to study the conductivity as a function of temperature $(500 \mathrm{~K}$ to $950 \mathrm{~K}$ ) for hot pressed samples of AlN having different volume percentage of porosity $(0.2,4,9$ and $15 \%)$. The effect of moisture on electrical conductivity has also been studied on the same samples by keeping annealed samples in air for a certain time period.

Section 2 describes the experimental details. Results have been presented and discussed in section 3. The 
last section deals with the conclusions of the present work.

\section{Experimental details.}

Hot pressed samples of AlN having different volume percentage of porosity were obtained from the Laboratoire de Céramique Nouvelles, Université de Limoges (France), These samples were prepared using commercial powder of AlN $(99 \%$ pure, grain size $<50 \mu \mathrm{m}$ ) obtained from Koch Light, U.K. Hot pressing was done by applying a pressure $\sim 20 \mathrm{MPa}$ for about $30 \mathrm{~min}$ at temperatures between 1500 to $1700^{\circ} \mathrm{C}$. The samples were in the form of pellets (dia $\sim 1.5 \mathrm{~cm}$ and thickness $\sim 0.5 \mathrm{~cm}$ ).

Electrical conductivity was measured by mounting the sample (sandwitched between two steel electrodes) inside a sample holder where temperature was varied from room temperature to $950 \mathrm{~K}$ and a vacuum $\sim 10^{-2}$ torr was maintained in the entire temperature range. The temperature was measured by mounting chromel-alumel thermocouple near to the sample.

A d.c. voltage of 30 volts was applied across the sample and the resulting current was measured using a 3 and $1 / 2$ digit digital pico-ammeter (Achme, model SD-100) having a least count of $1 \mathrm{PA}$ in the lowest range. The heating rate was kept quite small $(2 \mathrm{~K} / \mathrm{min})$ for the measurement of conductivity at different temperatures.

Unco a ted pellets were used for the conductivity measurements. Though the use of uncoated pellets raises the question of contact uniformity, uncoated pellets were preferred for the present measurements to avoid the electrode migration into the sample at high temperatures. A small error due to nonuniform contact will not change the conclusions of the present study significantly as the results are compared with each other under the same experimental conditions and the relative error will therefore not be too large.

For annealing, the samples were mounted in the sample holder and the temperature was varied slowly to $800 \mathrm{~K}$ in a vacuum $\sim 10^{-2}$ torr. After annealing the sample for one hour, they were cooled to room temperature inside the sample holder in the presence of vacuum. The temperature was again raised slowly to measure conductivity as a function of temperature.

The effect of moisture was studied by keeping the sample in a open container in air having no significant pollution and mean relative humidity $65 \%$ for a known time period. The conductivity was again measured in presence of a vacuum $\sim 10^{-2}$ torr but without annealing in this case.

\section{Results and discussions.}

3.1 EFFECT OF POROSITY ON ELECTRICAL CONDUCTIVITY. - Figure 1 shows the temperature dependence of conductivity $(\sigma)$ for hot pressed samples of AIN having different volume percentage of porosity $(0.2$, 4,9 and $15 \%$ ). These measurements were made after annealing the sample in vacuum. It is clear from figure 1

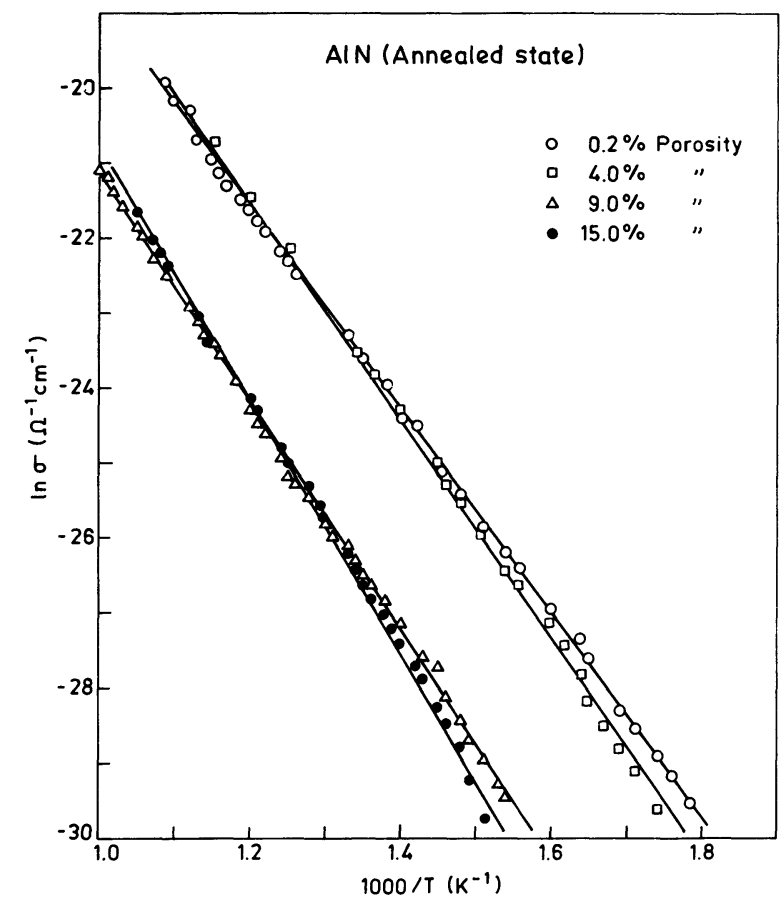

Fig. 1. - Temperature dependence of conductivity of hot pressed samples of AlN in annealed state having different volume percentage of porosity.

that $\ln \sigma v s .1000 \mid T$ curves are straight lines showing the presence of an activated process for electrical conduction. The conductivity can, therefore, be written as

$$
\sigma=\sigma_{0} \exp \left(-\frac{\Delta E}{k T}\right)
$$

where $\Delta E$ is known as the activation energy for electrical conduction and $k$ is the Boltzmann's constant.

For all the four samples studied, the values of $\Delta E$ and $\sigma$ at a particular temperature $(650 \mathrm{~K})$ are given in table I and plotted in figure $2(\mathrm{a}-\mathrm{b})$. It is clear from this figure that $\sigma$ decreases and $\Delta E$ increases as the volume percentage of porosity increases. However, no linear relation is found between $\sigma$ and volume percentage of porosity.

The effect of porosity on electrical conductivity is generally interpreted using two phase model, one having small but finite conductivity of the solid phase and the other having very small (almost negligible) conductivity of the pores. Considering the simple model [10] of parallel slabs, the net conductivity $(\sigma)$, considering the current flow parallel to the slab, can be written as

$$
\sigma=f_{\mathrm{s}} \sigma_{\mathrm{s}}+f_{\mathrm{p}} \sigma_{\mathrm{p}}
$$

where $\sigma_{\mathrm{p}}$ and $\sigma_{\mathrm{s}}$ are the conductivity and $f_{\mathrm{p}}$ and $f_{\mathrm{s}}$ are the volume fraction of the pore and solid phase respectively. 
Table I. - Electrical parameters at $650 \mathrm{~K}$ for hot pressed samples of AlN having different volume percentage of porosity.

\begin{tabular}{ccc}
$\begin{array}{c}\text { Porosity } \\
\text { (volume percent) }\end{array}$ & $\begin{array}{c}\Delta E \\
(\mathrm{eV})\end{array}$ & $\begin{array}{c}\text { Conductivity }(\sigma) \\
\left(\Omega^{-1} \mathrm{~cm}^{-1}\right)\end{array}$ \\
\hline 0.2 & 1.17 & $3.4 \times 10^{-12}$ \\
4.0 & 1.26 & $2.6 \times 10^{-12}$ \\
9.0 & 1.32 & $1.3 \times 10^{-13}$ \\
15.0 & 1.41 & $1.1 \times 10^{-14}$
\end{tabular}
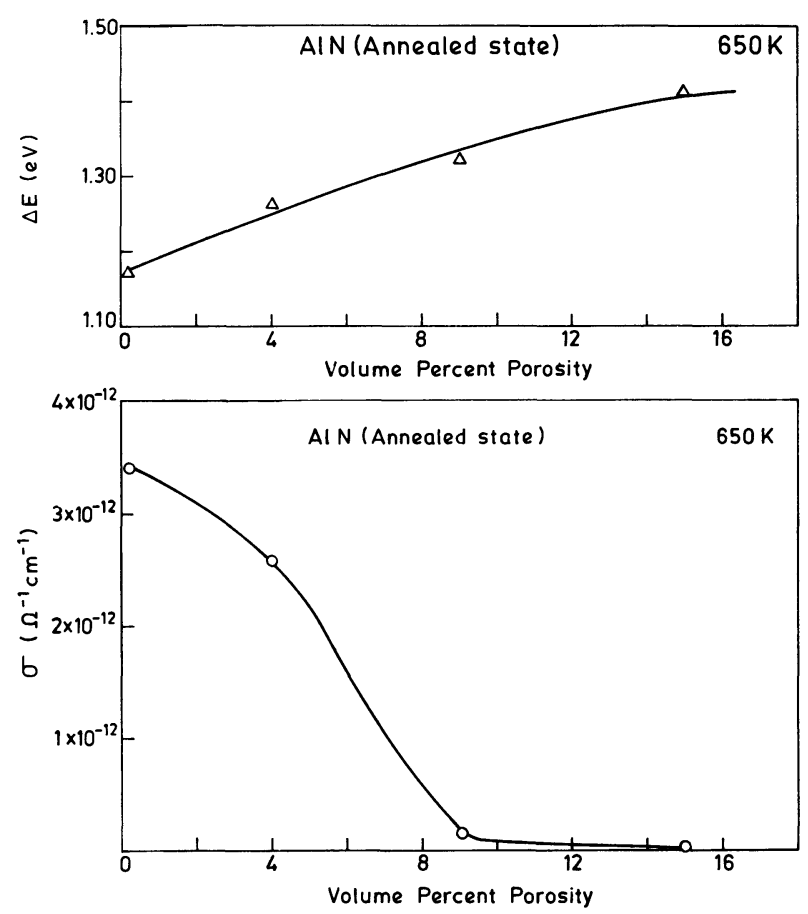

Fig. 2. - (a) Activation energy $(\Delta E)$ vs. volume percentage of porosity for hot pressed samples of $\mathrm{AlN}$ in annealed state. (b) Conductivity $(\sigma) v s$. volume percentage of porosity for hot pressed samples of AIN in annealed state.

Since $\sigma_{\mathrm{p}} \ll \sigma_{\mathrm{s}}$, the net conductivity $(\sigma)$ will decrease linearly with porosity as $f_{s}$ decreases linearly with the increase of porosity. The activation energy for conduction should however not depend upon porosity in the case of above analysis.

The above analysis is applicable only when isolated spherical pores are assumed in a continuous solid phase. When a continuous pore phase is assumed, the conductivity decreases much faster as porosity increases and levels off at higher porosity [10].

Our conductivity results figure $2 \mathrm{~b}$ show that the conductivity between 0.2 and 4 volume \% decreases slowly (a change by a factor of 1.3 only could be observed). However, when porosity increases further, a sharp decrease (by a factor of 20) in conductivity is observed between 4 and 9 volume \% of porosity. The conductivity levels off at higher porosity $15 \%$. This type of behaviour shows that the simple two phase model described above cannot be applied in the entire porosity range ( 0.2 to 15 volume $\%)$. Our results between 4 and 15 volume \%, however, seems to be closer to the case of continuous pore structure in solid phase. The different behaviour in the low porosity range $(\leqslant 4$ volume $\%)$ and high porosity range ( $>4$ volume $\%$ ) may be attributed to a transition from closed porosity to open porosity. This fact will be emphasized later in this paper.

3.2 EFFECT OF MOISTURE ON ELECTRICAL CONDUCTIVITY. - The effect of moisture on electrical conductivity has also been studied in all the four samples of hot pressed AlN having different volume percentage of porosity $(0.2,4,9$ and $15 \%)$. The samples having small percentage of porosity $(0.2$ and $4 \%)$ did not show an appreciable change in conductivity in the working temperature range. However, the samples having higher porosity showed an appreciable change in conductivity at all temperatures when exposed to air (mean relative humidity $65 \%$ ) after annealing. Figures 3 and 4 show the results of such measurements on hot pressed samples of AlN having volume percentage of porosity 9 and $15 \%$.

It is clear from figure 3 that conductivity increases by one order of magnitude after keeping the annealed sample in air for one month. The effect of moisture is much more in sample having $15 \%$ porosity (see Fig. 4). It is clear from this figure that an exposure of air for even one day changes the conductivity quite appreciably. After an exposure of one month, conductivity becomes three orders of magnitude higher than the annealed state at lower temperatures around $650 \mathrm{~K}$.

The effect of moisture can be understood by considering the absorption of water vapours into the pores and hence increasing the effective conductivity of the sample. As the sample is heated to higher temperatures, the water comes out of the pores and conductivity therefore decreases after annealing at higher temperatures. As the water comes out of the pores at different temperatures, the conductivity, unlike annealed samples, does not increase exponentially with single activation energy (see Fig. 4).

If the above explanation is accepted, the curves of figures 3 and 4 must meet at higher temperatures (more than the annealing temperature). However, our results of figures 3 and 4 show a difference in conductivity between annealed state and after moisture exposure even at the highest temperature used. This opens two possibilities (i) temperature rate during heating is high (ii) diffusion of oligo-elements during exposure to moisture.

No irreversible change was found after moisture exposure as after annealing for one hour again, the moist sample returns back to its original annealed state. The possibility of the diffusion of oligo-elements may therefore be neglected in the present case. The difference in the curves of figures 3 and 4 at higher 


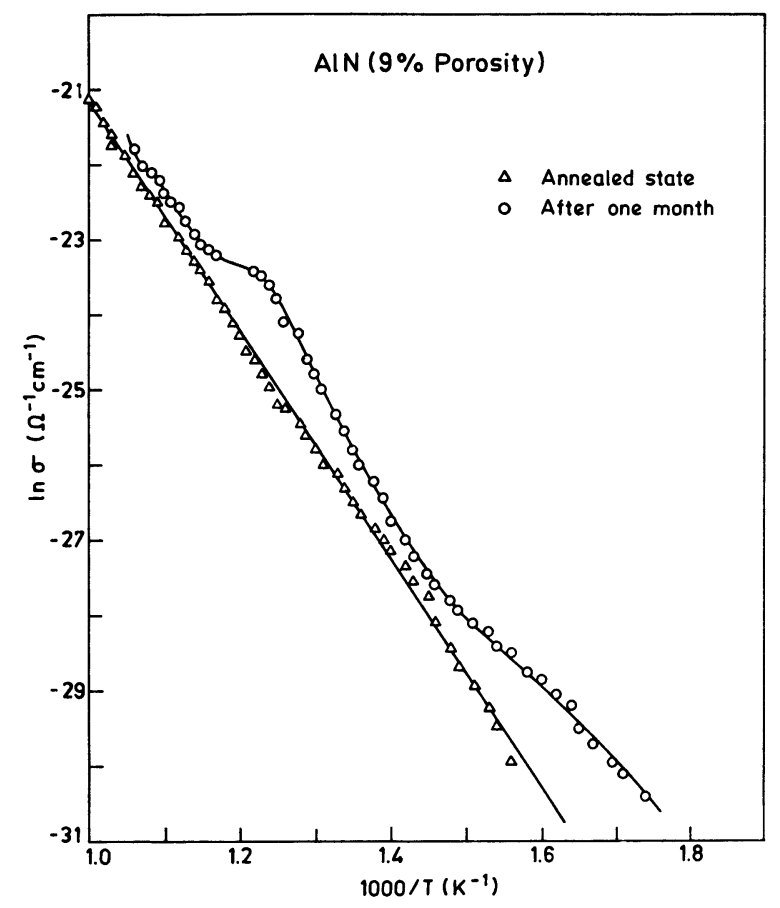

Fig. 3. - Temperature dependence of conductivity of hot pressed sample of AlN having $9 \%$ volume porosity in annealed state and after exposure to air.

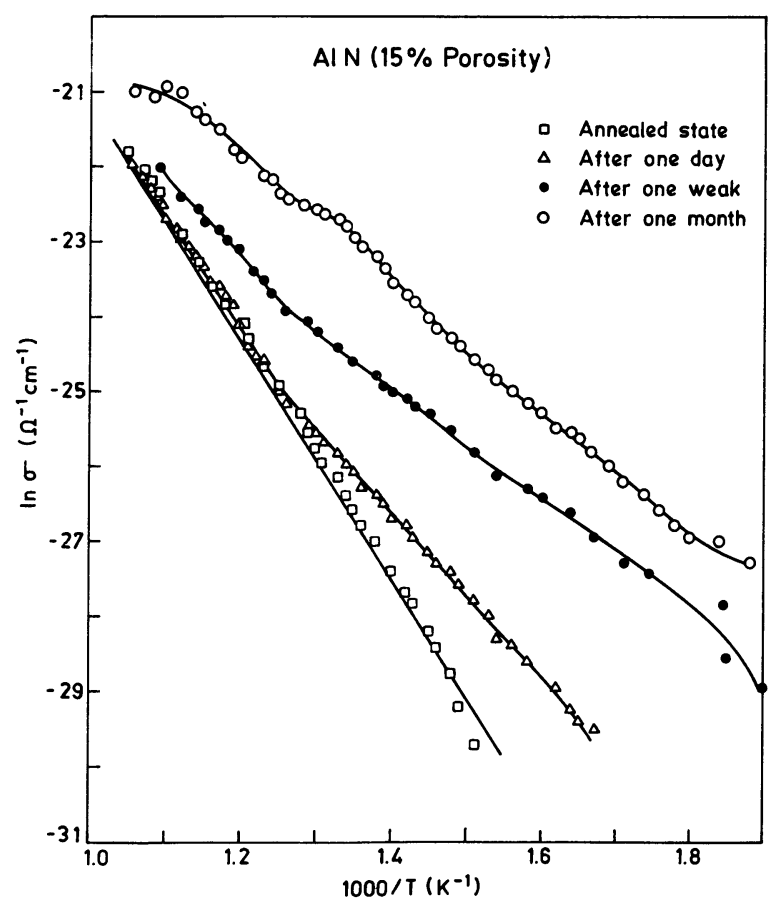

Fig. 4. - Temperature dependence of conductivity of hot pressed sample of AlN having $15 \%$ volume porosity in annealed state and after exposure to air.

temperatures may be attributed to the slightly higher heating rate.

Our results of moisture exposure on electrical conductivity show a sharp difference for samples having low porosity ( $\leqslant 4$ volume $\%$ ) where no change in conductivity was observed and for higher porosity $(\geqslant 9$ volume $\%$ ) where an appreciable change in conductivity has been observed (see Figs. 3 and 4). These results show a drastic change in the nature of pores as the volume percentage of porosity changes from 4 to $9 \%$.

Boch et al. [11] at the University of Limoges (France) from where the samples for the present study have been obtained, have measured the closed and open porosity as a function of total porosity in hot pressed AlN samples. They have reported [11] that at low percentage of total porosity (up to 6 volume \%), the open porosity is almost negligible and samples have mostly closed porosity. However, as the total porosity increases more than 6 volume \%, the open porosity increases rapidly and closed porosity starts decreasing after attaining a maximum.

From the above discussion, it is clear that in samples having 0.2 and $4 \%$ porosity, the closed porosity is dominant over the open porosity. However, in samples having 9 and 15 volume \% porosity, open porosity is dominant over the closed porosity. A sharp transition from closed to open porosity can; therefore, be accepted when porosity increases from 4 to 9 volume $\%$. This is probably the reason why the samples having porosity $\leqslant 4$ volume $\%$ show negligible effect of moisture exposure and samples having 9 and $15 \%$ porosity show an appreciable effect of moisture exposure on electrical conductivity (see Figs. 3 and 4).

\section{Conclusions.}

Temperature dependence of conductivity has been studied for hot pressed samples of AlN having different volume percentage of porosity. The effect of moisture has also been studied on the same samples. From these studies, the following conclusions can be drawn.

i) The electrical conductivity of hot pressed AlN ceramic is quite small $\left(<10^{-11} \Omega^{-1} \mathrm{~cm}^{-1}\right)$ below $650 \mathrm{~K}$. The conductivity increases exponentially as the temperature is increased and at higher temperatures $(950 \mathrm{~K})$, an appreciable conductivity $\left(>10^{-8} \Omega^{-1} \mathrm{~cm}^{-1}\right)$ is observed in these samples.

ii) The electrical conductivity decreases by two orders of magnitude as the porosity increases from 0.2 to 15 volume percent. The activation energy increases with the increase of porosity.

iii) The effect of moisture is negligible at low concentration of porosity (up to $4 \%$ ). However, at higher concentration of porosity ( 9 to $15 \%$ ), conductivity increases quite appreciably when annealed samples are exposed to air. These results show that a transition from closed porosity to open porosity takes place as the total porosity increases from 4 to 9 volume \%. This is in agreement with Boch et al. [11].

iv) Low porosity samples of hot pressed AlN can be used for electrical insulation below $650 \mathrm{~K}$ without having appreciable effect of moisture absorption. 


\section{Acknowledgments.}

We are grateful to Prof. M. Billy of the University of Limoges (France) for preparing hot pressed samples of AlN and gifting the same to us through Dr. J. P. Lecompte of Ecole de Mines, St. Etienne (France).

\section{References}

[1] Kohn, J. A., Cotter, P. G. and Potter, R. A., Am. Mineral. 41 (1956) 355.

[2] REY, M., Silicate Industries 22 (1958) 453.

[3] Renner, Von Th., Z. Anorg. u. Allgen Chem. 298 (1959) 22.

[4] Long, G. and Foster, L. M., J. Am. Ceram. Soc. 42 (1959) 53.

[5] TAYLOR, K. M. and Lenie, C., J. Elect. Soc. 107 (1960) 308.

[6] Devin, C., Jarrige, J., Mexman, J., Rev. Int. Hautes Temp. Refract 19 (1982) 325.
[7] Yamada, O., Shimada, M. and Koizumi, M., J. Soc. Mater. Sci. Japan 32 (1983) 1269.

[8] Tkachenko, Yu G., Yulgugin, V. K., Dubovik, T. V., Sov Powder Metall. Met. Ceram. 22 (1983) 405.

[9] Kumar, A., Lecompte, J. P. and Moliton, A., Revue Phys. Appl. 17 (1982) 285.

[10] KINGERY, W. D., Introduction to Ceramics (John Wiley and Sons, Inc., New York) 1960.

[11] Boch, P., Glandus, J. C., JarRige, J., LeCompte, J. P. and Mexman, J., Ceramics Intern. 8 (1982) 34. 